\title{
Acute Infectious Diarrhea in Children
}

Sibylle Koletzko, Stephanie Osterrieder

\section{SUMMARY}

Background: Acute infectious enteritis is one of the more common childhood diseases worldwide, especially in the first three years of life. Every year, in Germany, one in six children under age 5 is taken to a physician at least once because of infectious diarrheal disease. $10 \%$ of the children presenting with rotavirus infection are admitted to hospital. The existing national and international recommendations for the treatment of acute infectious diarrheal disease are inadequately followed, despite the high level of evidence on which they are based.

Methods: Selective literature search based on national and international guidelines

Results and conclusions: The therapeutic goal is to replace the fluid and electrolyte losses resulting from diarrhea and vomiting. The administration of a hypotonic oral rehydration solution (ORS) is indicated to treat impending dehydration (infants aged up to 6 months with diarrhea and/or more than 8 watery stools in the last 24 hours and/or more than 4 episodes of vomiting in the last 24 hours), or when mild or moderate dehydration is already present. Oral rehydration with ORS given in frequent, small amounts over 3-4 hours is successful in more than $90 \%$ of cases. Regular feeding can be begun immediately afterward. Laboratory testing of blood or stool is usually unnecessary. Children who can be rehydrated orally or through a nasogastric tube should not be given intravenous fluids.

Dtsch Arztebl Int 2009; 106(33): 539-48 DOI: 10.3238/arztebl.2009.0539

Key words: diarrhea, vomiting, rotavirus, gastroenteritis, pediatric disease

Abteilung für Pädiatrische Gastroenterologie und Hepatologie, Dr. von Haunersches Kinderspital, Ludwig-Maximilians-Universität München: Prof. Dr. med. Koletzko, Stephanie Osterrieder

\section{Introduction}

Acute infectious enteritis (including gastroenteritis) remains one of the commonest causes of death among infants and children in developing countries (1). It is most commonly due to viral infection (e1).

In Europe, most cases take a mild to moderately severe course, and fatal outcomes are extremely rare. Nonetheless, acute enteritis is a common cause of hospitalization in Germany and leads to high expenditures on health care, not least because of nosocomial infection (2).

The younger the child, the greater the risk that fluid and electrolyte losses will lead to dehydration. The type of dehydration - isotonic, hypotonic, or hypertonic - is independent of the causative organism. Fluid losses resulting from diarrhea and vomiting can be as high as three times the circulating blood volume (80-125-250 $\mathrm{mL}$ per $\mathrm{kg}$ body weight per day). In order to keep the blood volume constant, the body extracts fluid from the intracellular space, leading to dehydration. Complications and hospitalization can usually be prevented by the early and adequate oral administration of a rehydration solution (glucose-electrolyte solution) and normal food for the child's age.

The evidence-based guidelines of the ESPGHAN (3), the GPGE guidelines (4), Cochrane analyses (5-7), and a selective review of the literature are the basis of this article.

The learning aims for the reader are:

- Acquiring knowledge of the causes, principal manifestations, complications, and basic diagnostic evaluation of acute infectious diarrheal illnesses in childhood

- Being able to state the therapeutic measures to be taken in ambulatory care (the doctor's office and the walk-in emergency service)

- Taking note of the possibilities for prevention.

\section{Incidence}

Infants and toddlers typically suffer from acute infectious gastroenteritis once or twice per year. 
BOX

\section{Structured Questionnaire for Children with Diarrhea}

Age:

- Duration of diarrhea

- Number of stools in past 24 hours

- Stool consistency

- Blood in stool

- Vomiting

If yes: how many times in past 24 hours?

- Fever

If yes: how high

- Urine

- Fluid intake in past 24 hours:

- Food intake in past 24 hours

(infant formula, breast milk, pap, solid food):

\begin{tabular}{lc}
\hline - Is the child breast-fed? & yes / no \\
- Medications taken in the past 24 hours? & \\
Glucose/electrolyte solution & yes / no \\
Antipyrexic suppositories & yes / no \\
Other & yes / no \\
\hline & \\
\hline & Travel abroad in the past 2 weeks? \\
- Has the child been in contact with other persons with diarrhea/vomiting? \\
Persons living in the same household \\
Day-care / kindergarten / school & yes / no \\
- Any preexisting illness? & yes / no / unknown \\
If yes, what kind? & yes / no
\end{tabular}

Further important information:

Diagnostic questionnaire for diarrrheal illnesses developed by the author for the Dr. von Hauner Children's Hospital, Munich

\section{Definition}

Acute enteritis is defined as a loss of stool consistency, with pasty or liquid stools, and/or an increase in stool frequency to more than three stools in 24 hours, with or without fever or vomiting. Diarrhea usually lasts less than 7 days; if it lasts longer than 14 days, it is called protracted diarrhea (1). In the first few months of life, changes of stool consistency compared to the usual situation for the individual child are a more significant indication of an acute diarrheal illness than stool frequency.

\section{Epidemiology}

Infectious enteritis is very common in infancy and early childhood. Children up to age 3 have an average of one to two episodes per year, with peak incidence between the ages of 6 and 18 months. Every sixth child under age 5 in Germany is taken to see a physician at least once per year because of acute gastroenteritis (8).

\section{Causes}

About $40 \%$ of cases of acute diarrheal illness in the first 5 years of life are caused by rotaviruses, while a further $30 \%$ are caused by other viruses, mainly noroviruses and adenoviruses (8). In about $20 \%$ of affected children, a bacterial pathogen can be identified in the stool (Campylobacter jejuni, yersinia, salmonella, shigella, pathogenic E. coli, or clostridium difficile). Parasites are the cause in fewer than $5 \%$ (lamblia, cryptosporidia, Entamoeba histolytica, and others).

\section{Clinical manifestations}

Regardless of the particular causative organism, the patient generally develops watery stools, sometimes mixed with blood, after an incubation period of one to seven days. Vomiting and fever can precede or follow the diarrhea, or be absent entirely. The further manifestations depend on the degree of fluid and electrolyte loss, i.e., the degree of dehydration. Rare complications include intussusception or toxic or hypovolemic shock with prerenal azotemia as an expression of severe dehydration. Epileptic convulsions can result from fluid and/or electrolyte shifts, or from hypoglycemia. Encephalitis is rarely seen. Vomiting usually stops within a few hours after adequate rehydration, and after a maximum of 48 hours; diarrhea usually stops in two to seven days.

\section{Causes}

About $70 \%$ of cases of acute gastroenteritis in children are caused by viruses, usually rotaviruses, noroviruses, and adenoviruses.

\section{Complications}

The possible complications of an acute diarrheal illness include dehydration, metabolic acidosis, impaired consciousness, convulsions, circulatory shock, and prerenal azotemia. 
Clinical estimation of the fluid deficit ${ }^{\star 1}$

\begin{tabular}{|c|c|c|c|}
\hline & $\begin{array}{l}\text { Minimal or no dehydration } \\
<3 \% \text { weight loss }\end{array}$ & $\begin{array}{l}\text { Mild to moderate dehydration } \\
3-8 \% \text { weight loss }\end{array}$ & $\begin{array}{l}\text { Severe dehydration } \\
\geq 9 \% \text { weight loss }\end{array}$ \\
\hline $\begin{array}{l}\text { General condition, } \\
\text { State of consciousness }\end{array}$ & Good, awake & $\begin{array}{l}\text { Agitated, irritable, or tired } \\
\text { unconscious }\end{array}$ & Apathetic, lethargic, \\
\hline Thirst & Normal & Thirsty, drinks vigorously & $\begin{array}{l}\text { Drinks poorly or cannot } \\
\text { drink at all }\end{array}$ \\
\hline Heart rate & Normal & Normal to elevated & $\begin{array}{l}\text { Tachycardia; with further } \\
\text { worsening, bradycardia }\end{array}$ \\
\hline Pulse quality & Normal & Normal to diminished & Thready or not palpable \\
\hline Respirations & Normal & Normal or deepened & Deep, acidotic breathing \\
\hline Eyes & Normal & Sunken & Deeply sunken \\
\hline Tears & Present & Diminished & Absent \\
\hline Mucous membranes & Moist & Dry & Dried out \\
\hline $\begin{array}{l}\text { Skin wrinkles } \\
\text { (turgor) }\end{array}$ & Disappear immediately & $\begin{array}{l}\text { Disappear after } \\
\text { a delay of }<2 \mathrm{sec} \text {. }\end{array}$ & $\begin{array}{l}\text { Remain for more } \\
\text { than } 2 \text { seconds }\end{array}$ \\
\hline Capillary filling & Normal & Slow & Markedly slowed \\
\hline Limbs & Warm & Cool & Cold, cyanotic \\
\hline Urine output & Normal to diminished & Diminished & Minimal \\
\hline
\end{tabular}

${ }^{* 1}$ Modified from (4)

\section{Diagnostic evaluation}

In acute enteritis, the most important diagnostic step is clinical assessment of the degree of dehydration. The further diagnostic evaluation concerns the potential complications or differential diagnoses that may lie behind the clinical presentation of infectious enteritis. Good history-taking and physical examination is the foundation of the diagnostic evaluation. In severe cases, when complications arise, or when the diagnosis is in doubt, further studies must be performed.

\section{History}

History-taking should follow a structured procedure, as the information obtained will largely determine the further diagnostic and therapeutic measures to be taken. It helps, for example, to use a questionnaire of the type developed at the Dr. von Hauner Children's Hospital in Munich (Box), which is filled out in the walk-in emergency service either by the parents themselves or else by the physician on the basis of their verbal responses. The most important pieces of information concern the onset and frequency of diarrhea and vomiting, the intake of fluids and food, urine production, and fever. The parents are asked about the child's intake of medications, any preexisting illnesses (e.g., metabolic or intestinal conditions or disorders of immunity), and any possible exposures resulting from recent travel abroad, hospitalization, or contact with ill persons. If the patient has bloody stool and there is suspicion of a bacterial infection, particularly one caused by enterohemorrhagic E. coli (EHEC), the parents should be asked about the consumption of unpasteurized milk or uncooked meat and possible contact with cows.

\section{Physical examination}

Every child should be examined and weighed with clothes off. The extent of dehydration and fluid loss can be estimated (Table).

\section{Further diagnostic testing}

A stool sample should be sent for culture only if the findings will have clinical consequences. This is not the case for most children with infectious enteritis in Germany. The yield of positive determinations is low, while the

\section{History}

History-taking should follow a structured procedure, as the information obtained will largely determine the further diagnostic and therapeutic measures to be taken.

\section{Blood tests}

Blood tests and a stool test to determine the infectious organism are generally unnecessary in mild to moderate cases of diarrheal illness. 
cost of such studies is high. The demonstration of viruses and most types of bacteria causing enteritis would be of no therapeutic consequence for the individual patient. The results of a stool culture are often not available until two to three days after the sample is obtained, by which time the diarrhea has usually improved or resolved (3).

Nonetheless, a search for the causative organism by culture, direct demonstration of an antigen or toxin, or molecular genetic methods is recommended in the following situations:

- Nosocomial infection in hospitalized patients, i.e., onset of diarrhea more than three days after admission

- Severe course, with an estimated loss of more than $9 \%$ of total body weight

- Bloody diarrhea

- Recent travel to high-risk countries (Africa, Asia, Central and South America)

- Congenital or acquired immune deficiency or immunosuppressive therapy

- Suspected Clostridium difficile colitis or hemolyticuremic syndrome

- Infants under 4 months of age, particularly prematurely born infants

- Other ill persons in the child's environment, with suspicion of food poisoning

- Persistent diarrhea (for more than two weeks), if a positive result might lead to the administration of antibiotics.

Blood tests are generally not necessary in cases of mild or moderate dehydration, because the results do not influence the treatment (oral rehydration and feeding). Viral and bacterial causation cannot be distinguished from each other reliably on the basis of inflammatory parameters such as the C-reactive protein and the erythrocyte sedimentation rate $(3,9)$. Blood tests are indicated for severely dehydrated patients and/or those who will undergo IV rehydration. These should include a complete blood count, acid-base status, glucose, electrolytes, creatinine, and blood urea nitrogen. The urine output should be monitored in all patients with severe dehydration, impaired renal function, or suspected infection with enterohemorrhagic E. coli (EHEC).

\section{Differential-diagnostic studies}

If a urinary tract infection is suspected, the urine should be tested. Ultrasonography or another type of imaging study is indicated if there is clinical suspicion of intussusception. Endoscopic procedures for the obtaining of biopsy samples are reserved for special situations, e.g., in patients with an underlying illness to exclude other possible diagnoses, such as chronic inflammatory bowel disease

\section{Treatment \\ Symptomatic treatment}

The foundation of treatment is fluid and electrolyte replacement and the enteric administration of food to prevent or correct a catabolic state and to promote enterocyte regeneration. Infectious diarrheal illnesses are usually self-limiting. In mild cases, increased fluid administration combined with normal or reduced feeding often suffices to prevent dehydration. When the losses are greater because of numerous, watery stools and/or frequent vomiting, so that dehydration becomes clinically manifest, the patient should be rehydrated with oral rehydration solution (ORS) and then given appropriate food for age. Continuing losses due to persistent diarrhea or vomiting can be most safely replaced by the administration of ORS between meals (e.g., $10 \mathrm{~mL} / \mathrm{kg}$ for each watery stool). Longer interruptions of feeding or the maintenance of a reduced-calorie "gentle" or "build-up" diet for several days can delay recovery and increase the risk of a post-enteritic syndrome with protracted diarrhea.

\section{Oral rehydration for patients with clinically manifest dehydration ( $>3 \%$ weight loss)}

ORS was developed after the discovery of a coupled cotransport of sodium and glucose in enterocytes. Sodium is more effectively taken up from the intestinal lumen by the sGLT1 transporter if it is present together with glucose or galactose. Water then passively follows the sodium influx. ORS is hypo-osmolar and contains sodium and glucose in an optimal ratio for maximal uptake of sodium and water. It should thus be given in the prescribed dilution in water and not be mixed with other beverages (milk, juices, soft drinks).

Mildly or moderately dehydrated children should receive their calculated fluid loss in the form of ORS in multiple, divided portions over 3 to 4 hours. In mild dehydration ( $3 \%$ to $5 \%$ ), the amount to be given is 30 to 50 $\mathrm{mL}$ per $\mathrm{kg}$ of body weight; in moderate dehydration (>5\% to $8 \%$ ), the amount is 60 to $80 \mathrm{~mL}$ per $\mathrm{kg}$ of body weight, over 3 to 4 hours. For school-age children and adults, the amounts to be given per $\mathrm{kg}$ of body weight are lower. The success of rehydration should be assessed by a second physical examination and weighing of the

\section{Treatment}

„Tea breaks, " withholding of food for more than 4 to 6 hours, and a low-fat "build-up" diet for several days are obsolete treatments for acute diarrheal illness in infants and toddlers.

\section{Oral rehydration}

Oral rehydration with hypotonic rehydration solution is the treatment of choice (evidence level 1A). It is applicable, and successful, in $90 \%$ of children with mild to moderate dehydration. 
child at the end of the rehydration phase. For example, if a $10-\mathrm{kg}$ child loses $5 \%$ of its weight by dehydration, then the fluid loss is $500 \mathrm{~mL}$, and it follows that $125 \mathrm{ml}$ per hour should be given over four hours, or $170 \mathrm{~mL}$ per hour over 3 hours.

Since May 2002, the WHO has recommended a hypotonic solution with a maximum sodium content of $75 \mathrm{mmol} / \mathrm{L}$. Because salt losses are lower in viral enteritis than in cholera, glucose-electrolyte solutions with a sodium content of 45-60 $\mathrm{mmol} / \mathrm{L}$ are used in industrialized countries (e-Table). The addition of bicarbonate and/or citrate leads to a more rapid correction of metabolic acidosis. ORS with complex carbohydrates (derived from rice or carrots) should be given to infants only when they have already been eating solid food, and therefore should not be given to infants that are less than 4 months old.

The procedure for oral rehydration in cases of mild to moderate dehydration is the same regardless of whether the patient is suffering from iso-, hypo-, or hypertonic dehydration. Thus, the determination of serum electrolyte concentrations and assessment of acid-base status have no therapeutic consequence and is unnecessary. The demonstration of metabolic acidosis or of hypo- or hypernatremia does not justify intravenous rehydration. A Cochrane analysis of 17 randomized controlled studies involving children with infectious enteritis $(n=1811)$ showed no significant difference between oral and intravenous therapy with respect to the risk of hypo- or hypernatremia, fluid intake in the first 6 hours, and weight gain (5). Diarrhea ended an average of almost 6 hours earlier in patients treated with oral as compared to intravenous rehydration, and their hospital stays were significantly shorter, by an average of 1.2 days. Fatal outcomes were rare, but three times more common in patients receiving intravenous rehydration (6 versus 2 ). Treatment failure necessitating a switch from oral to intravenous rehydration occurred in only 1 in 25 children. This high success rate- $94 \%$ - under study conditions with strict inclusion criteria for intravenous therapy disproves the notion, commonly espoused by physicians and nurses, that oral rehydration is often not possible.

Children often accept the rehydration solution more readily when it is chilled or given at room temperature. Flavoring also increases acceptance. In order to reduce the likelihood of vomiting, small quantities should be given with a teaspoon or a $5 \mathrm{~mL}$ syringe, e.g., one teaspoonful every 1-2 minutes. If these portions are tolerated without vomiting, the amount can be increased and the interval between administrations lengthened. It is essential for the success of treatment that the parents and nursing staff should themselves be convinced of the superiority of oral rehydration to intravenous therapy. If ORS is refused or vomited, the continuous administration of ORS through a nasogastric tube is significantly better than intravenous therapy with regard to the duration of diarrhea, the length of hospital stay, and cost (10).

The Figure is a flowchart for the therapeutic procedure followed in our hospital's walk-in emergency service. The goal is to hospitalize as few patients as possible in order to prevent nosocomial infection, while providing every child with safe and effective treatment. High-risk patients, i.e., those who are overtly dehydrated and/or have had more than 8 stools and/or more than 4 episodes of vomiting in the past 24 hours or are less than 6 months old, are treated under supervision and discharged home only when their intake of fluids and food is satisfactory. Parents should be well informed about the treatment in all cases.

Unfortunately, appropriate ORS treatment without prior laboratory testing in accordance with published guidelines is all too often not given to hospitalized patients, who are instead rehydrated intravenously. Questioning by the statutory insurance carriers' medical services about whether the child has been treated "only" with oral rehydration, and then discharged home within a few hours, contributes to this inappropriate practice. Most physicians' offices, walk-in emergency services, and hospitals provide no opportunity for several hours of supervised treatment, or for single-day or partial hospitalization of the affected infants and toddlers. When signs of dehydration are present, however, these potentially endangered children should not be removed from medical supervision and discharged home until they have been adequately rehydrated and can tolerate food. In Germany, the lack of implementation of evidence-based treatment for infectious enteritis in infants and children with imminent or actual dehydration is thus partly due to a lack of resources for ambulatory care and partial hospitalization; another contributory cause is the "rewarding" of intravenous therapy by the DRG system.

Hypertonic solutions, and the earlier WHO recommendation for a sodium concentration of $90 \mathrm{mmol} / \mathrm{L}$, are not recommended for children $(3,9)$. Nor are cola drinks suitable for rehydration, as they contain an excessively high concentration of sugar $(\geq 110 \mathrm{~g} / \mathrm{L})$, hardly any sodium, and sometimes hardly any potassium, and their osmolality is too high (up to $780 \mathrm{mOsm} / \mathrm{L}$ ).

\section{The rehydration phase}

In the first 3 to 4 hours (the rehydration phase), infants and toddlers receive the estimated volume of their fluid deficit in multiple portions of oral rehydration solution (ORS).

\section{The procedure for moderate dehydration}

When oral rehydration is given for mild to moderate dehydration, the procedure is the same regardless of whether an iso- hypo-, or hypertonic dehydration is present. 
Homemade mixtures of juice, sugar, salt, and water for rehydration are not recommended for children under five years of age: erroneous mixing is common, the content of such mixtures is highly variable, and small children with their labile fluid-electrolyte balance are thereby exposed to unnecessary risks.

\section{Dietary recommendations for children with acute diarrheal illnesses}

Children with mild to moderate dehydration should begin to receive their usual food no later than four to six hours after rehydration is started (evidence level 1A) (3, 11). As the enterocytes of the bowel take up their nutrients mainly from the intestinal lumen rather than from the blood, food intake is important for the regeneration of the enterocytes, which have been damaged by infection (12). Breast-fed infants can be given ORS in between feedings. A switch to infant formula or a special diet should be avoided during the diarrheal illness or in the period immediately after it in order not to provoke food intolerance. Infants that are not breast-fed should receive their usual formula in undiluted form in frequent, small portions. A switch to a special diet (so-called therapeutic diets with reduced lactose and/or fat content, dairy products based on soya protein or with hydrolyzed protein) is not indicated (e2). Infants being fed with hypoallergenic formula (HA formula) should receive no other kind of infant formula based on either whole cow's milk protein or soya protein. If the infant was already taking solid food before the episode of gastroenteritis, solid food can still be given. Toddlers are given food appropriate for their age, starting with food containing complex carbohydrates, such as bread, noodles, potatoes, rice, oatmeal or semolina porridge, pretzels, and soup (potato or carrot soup). As long as there is no vomiting, the child can be brought over to a normal toddler's diet with a normal fat content. Juices with a high fructose, saccharose, or sorbitol content, such as apple and pear juice, and very sweet foods (high osmolarity) should be avoided.

\section{Pharmacotherapy}

For most children with infectious diarrheal illnesses, treatment with medications is not indicated. Randomized controlled trials (RCTs) have shown that a few medications and food additives have a positive therapeutic effect when given as a supplement to ORS administration. They are, therefore, a reasonable medical option in some cases and can be used if their benefit is likely to outweigh their cost.

\section{Racecadotril}

This inhibitor of secretion has been found in three large-scale, randomized, controlled trials (of which two were of high quality) to shorten the duration of diarrhea significantly, by an average of 28 hours, and to reduce the stool volume by almost $50 \%$ in children with acute enteritis (13, 14). Racecadotril is an enkephalinase inhibitor that reduces pathologically increased secretion within a few hours in diarrhea of either viral or bacterial origin (15). It has no direct effect on intestinal motility and thus does not elevate the risk of constipation or pathological bacterial colonization, as does loperamide, for example (e3). No serious adverse effects have been reported. The medication is approved for use in infants aged 3 months and older.

\section{Probiotic agents}

The precise mechanisms of action of probiotic agents in acute, infectious diarrheal illnesses are unknown. Studies on the use of probiotically active bacteria (16, e4) and Saccharomyces bourlardii (17) have been of variable, usually poor, quality and have yielded inconsistent findings. They are therefore difficult to interpret, and no recommendation can be made regarding any particular type of probiotic agent (6, e4). A reduced duration of diarrhea has been shown with the use of some types of live bacteria (Lactobacillus ramnosus GG, Lactobacillus reuteri, Lactobacillus acidophilus, Lactobacillus bifidus, and E. coli Nissle) in rotavirus infection, but not in diarrhea of bacterial origin (18). Killed bacteria cannot be recommended for the treatment of diarrhea.

\section{Antiemetic agents}

Although multiple randomized, controlled trials have shown ondansetron to reduce vomiting and the need for intravenous rehydration, this medication has not been approved for infants and toddlers and seems to increase diarrhea while it is being given; thus, it cannot be recommended in this age group $(7,19)$. Dimenhydrinate is the most commonly prescribed antiemetic drug for children with acute infectious enteritis in Germany, despite the low level of evidence (20). In a randomized, controlled trial, one or two doses of dimenhydrinate were found to lower the frequency of vomiting but had no effect on weight gain or the duration of diarrhea. Adverse effects were no more common than with placebo (21).

\section{Oral is better than intravenous}

Infants and children that can be rehydrated orally or enterally should not be given intravenous fluids.

\section{Cola drinks}

Cola drinks and homemade juice-sugar-water mixtures are not suitable for the rehydration of infants and small children. 


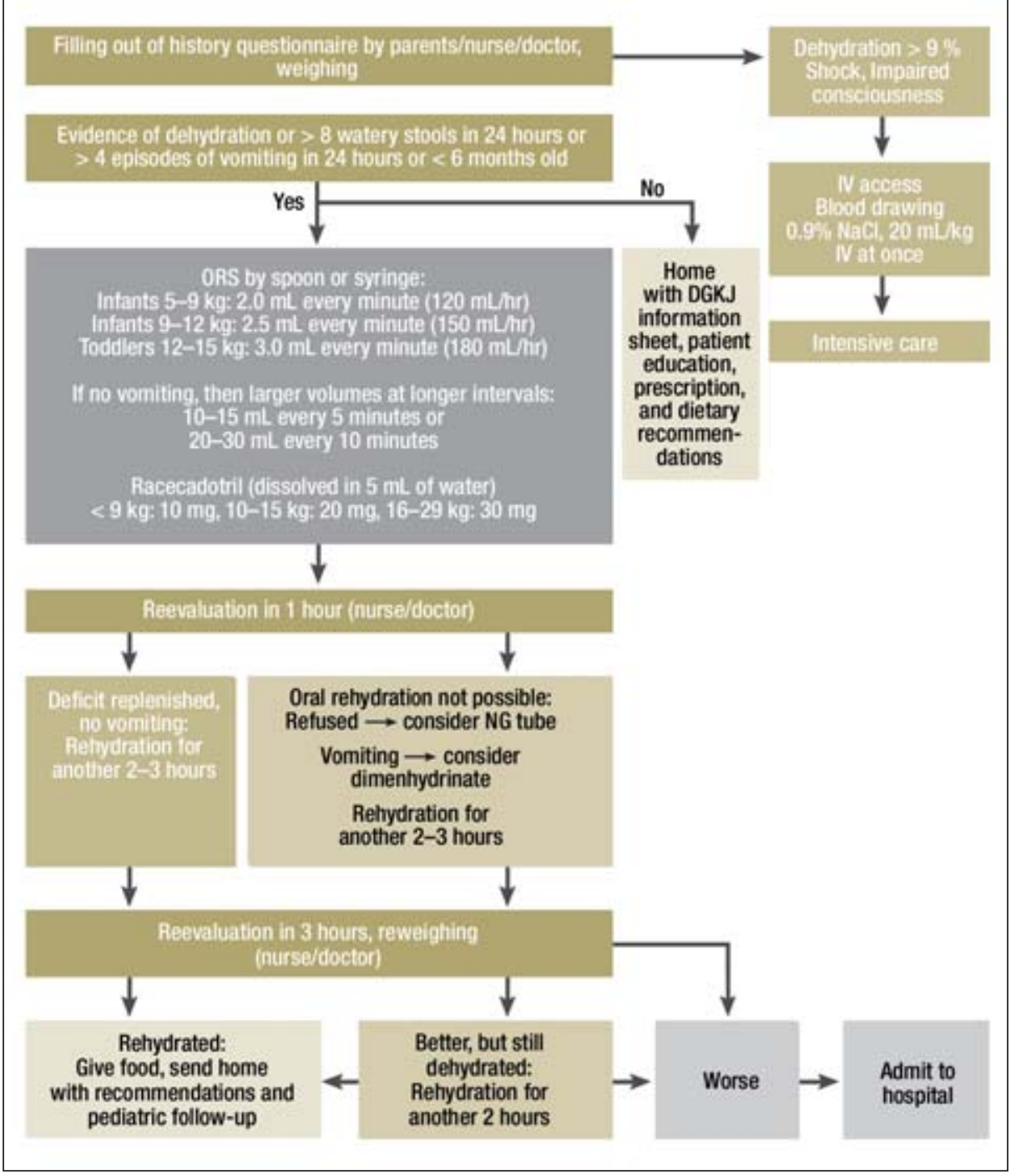

Flowchart for the procedure for infants and toddlers with acute,

infectious diarrheal illness, developed by the author for the walk-in emergency service of the Dr. von Hauner Children's Hospital, Munich, after (3); ORS, oral rehydration solution; DGKJ, Deutsche Gesellschaft für Kinder- und Jugendmedizin (The German Association for Pediatric and Adolescent Medicine)

\section{Antibiotics}

Specific anti-infectious treatment is not recommended for most children with acute diarrheal illnesses. Antibiotics are obligatory in cases of infection with Salmonella typhi, Vibrio cholerae, Entamoeba histolytica, and Giardia lamblia and for children over 1 year old with proven, toxin-positive Clostridium difficile colitis. Antibiotics are recommended for the treatment of diarrheal disease due to bacterial infection in the following situations or for the following types of patients: infants in the first three months of life, premature infants up to 52 weeks of post-conceptional age, children with primary or secondary immune deficiency, and children whose illness is complicated by sepsis. The following mediations are not recommended and/or not approved for the treatment of infants and toddlers with acute diarrheal illness, because they have no effect, or a deleterious effect, on the course of the illness: motility inhibitors such as loperamide,

\section{Probiotics}

Studies on the use of probiotically active bacteria and Saccharomyces bourlardii are of variable, mostly poor quality, and their findings are inconsistent.

\section{Nosocomial infections}

To avoid nosocomial infection, children with gastroenteritis should not be admitted to hospital unless medically necessary. 


\section{FURTHER INFORMATION}

- The German Association for Pediatric and Adolescent Medicine (Deutsche Gesellschaft für Kinder- und Jugendmedizin, DGKJ) and the Association for Pediatric Gastroenterology and Nutrition (Gesellschaft für Pädiatrische Gastroenterologie und Ernährung, GPGE) have jointly released a (Germanlanguage) information sheet for parents of children with acute diarrheal illnesses. Ilt can be seen on the Internet at www.dgkj.de and ordered free of charge from the DGKJ office.

- Further information on rotavirus vaccination (in German language) can be found on the following website: www.kinderaerzte-im-netz.de/bvkj/show.php3?id=138\&nodeid=

nonspecific adsorbents such as charcoal or kaolin-pectin, cholestyramine, and bismuth preparations. Smectite (silicate) is often given in France (20); studies of the use of this agent have yielded inconsistent results, but it was determined in a meta-analysis to shorten the duration of diarrhea (22). Whether it truly reduces fluid and electrolyte losses remains unclear. As smectite is a nonspecific adsorbent, it should be given in a temporal separation of at least 1.5 hours from other medications.

\section{Primary and secondary prevention}

- Mother's milk protects against infection, including acute infectious enteritis (23).

- General hygienic measures: manual hygiene, particularly after urination and defecation and after diaper changes, reduces the spread of infection in households and institutions. For hospitalized patients, hospital hygiene should be strictly adhered to: disposable gloves and gowns, hand disinfection, routine disinfection of surfaces with abrasive wipes, grouping affected patients together if possible, individual toilets. Treating personnel should also fulfill their duty to report according to the German Federal Communicable Diseases Act (Infektionsschutzgesetz, IfSG).

- Hygienic handling of food: bacterial infections acquired through food usually arise because of the consumption of incompletely cooked meat (yersinia, campylobacter, salmonella), raw eggs (salmonella), and unpasteurized milk (EHEC infections)

- Vaccination against rotavirus infection: Two oral vaccines for the primary prevention of rotavirus infection are now available in Germany. The rate of protection against severe rotaviral illness is higher than $95 \%$, as shown by a total of 11 randomized, controlled trials involving more than 146000 infants. Vaccination is recommended for all infants, including premature infants, by the European (ESPID, ESPGHAN) (24) and German specialty societies (DAKJ, GPGE, DGPI). Widespread vaccination in the USA from February 2006 onward has led to a dramatic reduction in hospitalizations and emergency treatment because of rotavirus infection (25). The German Standing Committee on Vaccinations (Ständige Impfkommission, STIKO) has not yet issued a general recommendation to vaccinate. The Vaccination Committees of two German states, Saxony (Ärzteblatt Sachsen, 12/2008) and Brandenburg (Amtsblatt für Brandenburg, No. 6, 2009), recommend the vaccination of all infants from the 7 th to the end of the 26th week of life. Some of the statutory health insurance carriers in Germany reimburse the cost of vaccination; it is thus worthwhile to address the matter of payment before vaccination is performed (see Information Box).

\section{Conflict of interest statement}

Professor Koletzko has received study support from Fresenius as well as lecture honoraria and consulting fees from Abbott, Danone, Fresenius, Hipp, and SanofiPasteur. Ms. Osterrieder has received support from Danone for participation in a scientific meeting.

Manuscript received on 11 May 2009; revised version accepted on 8 July 2009.

Translated from the original German by Ethan Taub, M.D

\section{REFERENCES}

1. Thapar N, Sanderson IR: Diarrhoea in children: an interface between developing and developed countries. Lancet 2004; 363: 641-53.

2. Soriano-Gabarro M, Mrukowicz J, Vesikari T, Verstraeten T: Burden of rotavirus disease in European Union countries. Pediatr Infect Dis J 2006; 25(1 Suppl): 7-11.

3. Guarino A, Albano F, Ashkenazi S et al.: European Society for Paediatric Gastroenterology, Hepatology, and Nutrition/European Society for Paediatric Infectious Diseases evidence-based guidelines for the management of acute gastroenteritis in children in Europe: executive summary. J Pediatr Gastroenterol Nutr 2008; 46(5): 619-21.

4. Koletzko S, Lentze MJ: Akute infektiöse Gastroenteritis. www.awmf.de 2008

5. Hartling L, Bellemare S, Wiebe N, Russell K, Klassen TP, Craig W: Oral versus intravenous rehydration for treating dehydration due to gastroenteritis in children. Cochrane Database Syst Rev 2006; 3 : CD004390.

6. Allen SJ, Okoko B, Martinez E, Gregorio G, Dans LF: Probiotics for treating infectious diarrhoea. Cochrane Database Syst Rev 2004 (2): $\mathrm{CD} 003048$

\section{Antibiotics}

A specific anti-infectious treatment is not recommended for the majority of children with acute diarrheal illness.

\section{Primary and secondary prevention}

\section{Breast feeding}

- General hygienic measures

- Hygienic handling of food

- Rotavirus vaccination 
7. Alhashimi D, Alhashimi H, Fedorowicz Z: Antiemetics for reducing vomiting related to acute gastroenteritis in children and adolescents. Cochrane Database Syst Rev 2006; (4): CD005506.

8. Van Damme P, Giaquinto C, Huet F, Gothefors L, Maxwell M, Van der WM: Multicenter prospective study of the burden of rotavirus acute gastroenteritis in Europe, 2004-2005: the REVEAL study. J Infect Dis 2007;195 (Suppl 1): 4-16.

9. Armon K, Stephenson T, MacFaul R, Eccleston P, Werneke U: An evidence and consensus based guideline for acute diarrhoea management. Arch Dis Child 2001; 85(2): 132-42.

10. Gremse DA: Effectiveness of nasogastric rehydration in hospitalized children with acute diarrhea. J Pediatr Gastroenterol Nutr 1995; 21(2): 145-8

11. King CK, Glass R, Bresee JS, Duggan C: Managing acute gastroenteritis among children: oral rehydration, maintenance, and nutritional therapy. MMWR Recomm Rep 2003; 52 (RR-16): 1-16.

12. Sandhu BK: Rationale for early feeding in childhood gastroenteritis. J Pediatr Gastroenterol Nutr 2001; 33(Suppl 2): 13-16.

13. Salazar-Lindo E, Santisteban-Ponce J, Chea-Woo E, Gutierrez M. Racecadotril in the treatment of acute watery diarrhea in children. $\mathrm{N}$ Engl J Med 2000 Aug 17; 343(7): 463-7.

14. Szajewska H, Ruszczynski M, Chmielewska A, Wieczorek J: Systematic review: racecadotril in the treatment of acute diarrhoea in children. Aliment Pharmacol Ther 2007; 26(6): 807-13.

15. Cezard JP, Duhamel JF, Meyer M, Pharaon I, Bellaiche M, Maurage C et al.: Efficacy and tolerability of racecadotril in acute diarrhea in children. Gastroenterology 2001; 120(4): 799-805.

16. Szajewska H, Skorka A, Ruszczynski M, Gieruszczak-Bialek D: Metaanalysis: Lactobacillus GG for treating acute diarrhoea in children. Aliment Pharmacol Ther 2007; 25: 871-81.

17. Szajewska H, Skorka A, Dylag M: Meta-analysis: Saccharomyces boulardii for treating acute diarrhoea in children. Aliment Pharmaco Ther 2007; 25: 257-64.

18. Guandalini S, Pensabene L, Zikri MA, Dias JA, Casali LG, Hoekstra H et al.: Lactobacillus GG administered in oral rehydration solution to children with acute diarrhea: a multicenter European trial. J Pediatr Gastroenterol Nutr 2000; 30: 54-60.

19. Szajewska H, Gieruszczak-Bialek D, Dylag M: Meta-analysis: ondansetron for vomiting in acute gastroenteritis in children. Aliment Pharmacol Ther 2007; 25(4): 393-400.

20. Pfeil N, Uhlig U, Kostev K, Carius R, Schroder H, Kiess W, et al.: Antiemetic medications in children with presumed infectious gastroenteritis - pharmacoepidemiology in Europe and Northern America. J Pediatr 2008; 153(5): 659-62.

21. Uhlig U, Pfeil N, Gelbrich G, Spranger C, Syrbe S, Huegle B et al.: Antiemetic activity of dimenhydrinate in children with infectious gastroenteritis - a prospective randomized controlled trial. J Pediatr 2009.

22. Szajewska H, Dziechciarz P, Mrukowicz J: Meta-analysis: Smectite in the treatment of acute infectious diarrhoea in children. Aliment Pharmacol Ther 2006; 23(2): 217-27.

23. Kramer MS, Kakuma R: The optimal duration of exclusive breastfeeding: a systematic review. Adv Exp Med Biol 2004; 554: 63-77.
24. Vesikari T, Van DP, Giaquinto C et al.: European Society for Paediatric Infectious Diseases/European Society for Paediatric Gastroenterology, Hepatology, and Nutrition evidence-based recommendations for rotavirus vaccination in Europe: executive summary. J Pediatr Gastroenterol Nutr 2008; 46: 615-8.

25. American Academy of Pediatrics, Committee on Infectious Diseases. Prevention of Rotavirus Disease: Updated Guidelines for Use of Rotavirus Vaccine. Pediatrics 2009; 30; 123.

\section{Corresponding author}

Prof. Dr. med. Sibylle Koletzko

Department of Pediatric Gastroenterology and Hepatology

Dr. von Hauner Children's Hospital

Ludwig Maximilians University, Munich

Lindwurmstr. 4

D80337 Munich

Germany

Sibylle.Koletzko@med.uni-muenchen.de

For e-references please refer to: www.aerzteblatt-international.de/ref3309 The eTable is available at: www.aerzteblatt-international.de/article09m539

\section{Further Information on GME}

This article has been certified by the North Rhine Academy for Postgraduate and Continuing Medical Education.

Deutsches Ärzteblatt provides certified continuing medical education (CME) in accordance with the requirements of the Chambers of Physicians of the German federal states (Länder). CME points of the Chambers of Physicians can be acquired only through the Internet by the use of the German version of the CME questionnaire within 6 weeks of publication of the article, i.e., by 25 September 2009. See the following website: cme.aerzteblatt.de

Participants in the CME program can manage their CME points with their 15-digit „uniform CME number" (einheitliche Fortbildungsnummer, EFN). The EFN must be entered in the appropriate field in the cme.aerzteblatt.de website under "meine Daten“ (,my data"), or upon registration. The EFN appears on each participant's CME certificate.

The solutions to the following questions will be published in issue 41/2009. The CME unit „Infective Endocarditis—Prophylaxis, Diagnostic Criteria, and Treatment" (issue 28-29/2009) can be accessed until 24 August 2009.

For issue 37/2009 we plan to offer the topic „The Medical and Surgical Treatment of Glaucoma."

Solutions to the CME questionnaire in issue 25/2009:

Müller-Lissner S: The Pathophysiology, Diagnosis, and Treatment of Constipation. Solutions: 1d, 2b, 3c, 4c, 5d, 6a, 7e, 8e, 9b, 10c 


\section{Please answer the following questions to participate in our certified Continuing Medical Education program. Only one answer is possible per question. Please select the answer that is most appropriate.}

\section{Question 1}

The peak frequency of acute gastroenteritis occurs in what age range?
a) $0-6$ months
b) 6-18 months
c) $18-36$ months
d) 36-44 months
e) 44-72 months

\section{Question 2}

Which of the following most commonly cause acute gastroenteritis in childhood?
a) Adenoviruses
b) Campylobacter jejuni
c) Noroviruses
d) Rotaviruses
e) Salmonella

\section{Question 3}

Which of the following manifestations definitely indicates dehydration in acute gastroenteritis?
a) Moist mucous membranes
b) Deeply sunken eyes
c) Nuchal rigidity
d) Increased production of tears
e) Skin wrinkles that disappear immediately

\section{Question 4}

Under what circumstances should the serum electrolyte concentrations always be measured in an 18-month-old child before treatment for infectious gastroenteritis?
a) $500 \mathrm{~g}$ weight loss
b) Lightly blood-tinged stool
c) Fever to $39^{\circ} \mathrm{C}$
d) Prolonged lack of food intake
e) Before IV rehydration if vomiting cannot be brought under control

Question 5

What investigation should be performed before rehydration is begun?
a) Measurement of height and weight for calculation of the BMI
b) Weighing of the unclothed child
c) Blood glucose measurement
d) Blood pressure measurement
e) Counting of heart rate and respirations

\section{Question 6}

What is the basis of the therapeutic effect of oral rehydration?
a) Coupled $\mathrm{Na}^{+} / \mathrm{K}^{+}$co-transport in the enterocyte
b) Coupled $\mathrm{Na}^{+} /$bicarbonate co-transport in the enterocyte
c) Coupled $\mathrm{Na}^{+} /$glucose co-transport in the enterocyte
d) Coupled $\mathrm{K}^{+} /$galactose co-transport in the enterocyte
e) Inhibition of pathological secretion in the small intestine

\section{Question 7}

In oral rehydration, the estimated weight loss is replaced with oral rehydration solution (ORS). How rapidly should the calculated volume be administered to a 2-year-old child?

a) Over 1-2 hours

b) Over 3-4 hours

c) Over 6-8 hours

d) Over 24 hours in divided boluses before meals

e) The time span over which oral rehydration is given is immaterial

\section{Question 8}

Which of the following is particularly important with regard to the feeding of fully breast-fed infants with acute gastroenteritis?

a) Fully breast-fed infants should be rehydrated intravenously.

b) Breastfeeding should be temporarily stopped and oral rehydration solution should be given exclusively.

c) The child should be weaned to a diet containing hydrolyzed protein.

d) The child should be weaned to low-fat infant formula.

e) Breastfeeding should continue in between doses of oral rehydration solution.

\section{Question 9}

When should a causative organism for an acute diarrheal illness be sought in the stool?

a) In all infants under 1 year old that are still being fully breast-fed

b) When the child's temperature exceeds $39^{\circ} \mathrm{C}$ for 24 hours or more

c) In a 4-year-old child with lightly blood-tinged diarrhea after drinking unpasteurized milk on a visit to a farm

d) When more than two family members or persons living in the same house are ill

e) In a 5-year-old child 5 days after the initiation of penicillin treatment for purulent tonsillitis

\section{Question 10}

Which of the following contraindicates rehydration with ORS per os or by nasogastric tube?

a) Severe dehydration with prerenal azotemia

b) Hypertonic dehydration

c) Hypotonic dehydration

d) Metabolic acidosis

e) All of the above 
CONTINUING MEDICAL EDUCATION

\section{Acute Infectious Diarrhea in Children}

Sibylle Koletzko, Stephanie Osterrieder

\section{e-REFERENCES}

e1. Oh DY, Gaedicke G, Schreier E: Viral agents of acute gastroenteritis in German children: prevalence and molecular diversity. J Med Virol 2003; 71: 82-93.

e2. Conway SP, Ireson A: Acute gastroenteritis in well nourished infants: comparison of four feeding regimens. Arch Dis Child 1989 Jan; 64: 87-91.

e3. Turck D, Berard H, Fretault N, Lecomte JM: Comparison of racecadotril and loperamide in children with acute diarrhoea. Aliment Pharmacol Ther 1999; 13(Suppl 6): 27-32.

e4. Guarino A, Lo VA, Canani RB: Probiotics as prevention and treatment for diarrhea. Curr Opin Gastroenterol 2009; 25: 18-23. 


\title{
Acute Infectious Diarrhea in Children
}

\author{
Sibylle Koletzko, Stephanie Osterrieder
}

\section{e-TABLE}

The composition of ORS preparations suitable for the rehydration of infants and children that are now commercially available in Germany*1

\begin{tabular}{|c|c|c|c|c|}
\hline \multicolumn{5}{|c|}{ Glucose-based preparations: } \\
\hline & $\begin{array}{l}\text { ESPGHAN } \\
\text { recommen- } \\
\text { dation }\end{array}$ & $\begin{array}{l}\text { GES 60TM (Milupa, } \\
\text { Germany) }\end{array}$ & $\begin{array}{l}\text { Humana Elektrolyt }{ }^{\mathrm{TM}} \\
\text { Banana (12 months } \\
\text { and older) } \\
\text { (Humana, Germany) }\end{array}$ & $\begin{array}{l}\text { Humana Elektrolyt } \\
\text { Fennel } \\
\text { (infants, children, adults) } \\
\text { (Humana, Germany) }\end{array}$ \\
\hline Sodium (mmol/L) & 60 & 60 & 60 & 60 \\
\hline Potassium (mmol/L) & 20 & 20 & 20 & 18 \\
\hline Chloride (mmol/L) & 25 & 50 & 50 & 49 \\
\hline Bicarbonate (mmol/L) & 0 & 0 & 0 & 0 \\
\hline Citrate (mmol/L) & 10 & 10 & 10 & 10 \\
\hline Glucose (mmol/L) & $74-111$ & 110 & 86 & 87 \\
\hline Glucose (g/L) & $13.3-20.0$ & 20 & 16 & 16 \\
\hline \multirow{2}{*}{$\begin{array}{l}\text { Osmolarity (m0sm/L) } \\
\text { maltodextrin }\end{array}$} & $200-250$ & 240 & 230 & 188 \\
\hline & $\begin{array}{l}\text { ESPGHAN } \\
\text { recommen- } \\
\text { dation }\end{array}$ & $\begin{array}{l}\text { Oralpädon } 240^{\mathrm{TM}} \\
\text { (Stada, Germany) }\end{array}$ & $\begin{array}{l}\text { Santalyt }{ }^{\mathrm{TM}} \\
\text { (Medice, } \\
\text { Germany) }\end{array}$ & $\begin{array}{l}\text { InfectoDiarrstop LGGTM } \\
\text { (Infectopharm, Germany) }\end{array}$ \\
\hline Sodium (mmol/L) & 60 & 60 & 60 & 60 \\
\hline Potassium (mmol/L) & 20 & 20 & 20 & 20 \\
\hline Chloride (mmol/L) & 25 & 60 & 60 & 50 \\
\hline Bicarbonate (mmol/L) & 0 & 0 & 0 & 0 \\
\hline Citrate (mmol/L) & 10 & 10 & 10 & 10 \\
\hline Glucose (mmol/L) & $74-111$ & 90 & 90 & 111 \\
\hline Glucose (g/L) & $13.3-20.0$ & 16,2 & 16,2 & 20 \\
\hline Osmolarity (m0sm/L) & $200-250$ & 240 & 240 & 251 \\
\hline \multicolumn{5}{|c|}{ Preparations with carbohydrate polymers: } \\
\hline & $\begin{array}{l}\text { ESPGHAN } \\
\text { recommen- } \\
\text { dation }\end{array}$ & \multicolumn{2}{|c|}{$\begin{array}{l}\text { ORS } 200 \text { Carrot-Rice PapTM } \\
\text { (Hipp, Germany) }\end{array}$} & $\begin{array}{l}\text { Rice pap-electrolyte diet } \\
\text { (Töpfer, Germany) }\end{array}$ \\
\hline Sodium (mmol/L) & 60 & \multicolumn{2}{|l|}{55} & 55 \\
\hline Potassium (mmol/L) & 20 & \multicolumn{2}{|l|}{25} & 30 \\
\hline Chloride (mmol/L) & 25 & \multicolumn{2}{|l|}{40} & 60 \\
\hline Bicarbonate (mmol/L) & 0 & \multicolumn{2}{|l|}{0} & 25 \\
\hline Citrate $(\mathrm{mmol} / \mathrm{L})$ & 10 & \multicolumn{2}{|l|}{7} & 0 \\
\hline $\begin{array}{l}\text { Carbohydrates(g/L)(total) } \\
\text { Glucose (mmol/L) } \\
\text { Glucose }(\mathrm{g} / \mathrm{L})\end{array}$ & $\begin{array}{l}74-111 \\
13.3-20.0\end{array}$ & \multicolumn{2}{|l|}{$\begin{array}{l}42 \\
67 \\
12\end{array}$} & $\begin{array}{l}46 \\
28 \\
5\end{array}$ \\
\hline Osmolarity (m0sm/L) & $200-250$ & \multicolumn{2}{|l|}{240} & 220 \\
\hline
\end{tabular}

*1The trade names and manufacturers of these preparations are listed here (not the usual practice of Deutsches Ärzteblatt) because the active substances are not named. All preparations currently in use in Germany are listed. Note: Oralpädon ${ }^{\mathrm{TM}} 240$ (strawberry and apple-banana flavor), Santalyt ${ }^{\mathrm{TM}}$, and InfectoDiarrstop LGGTM contain aspartame and are therefore contraindicated for patients with phenylketonuria. 